\title{
QUANTITATIVE CHEMICAL ANALYSIS
}


This page intentionally left blank 


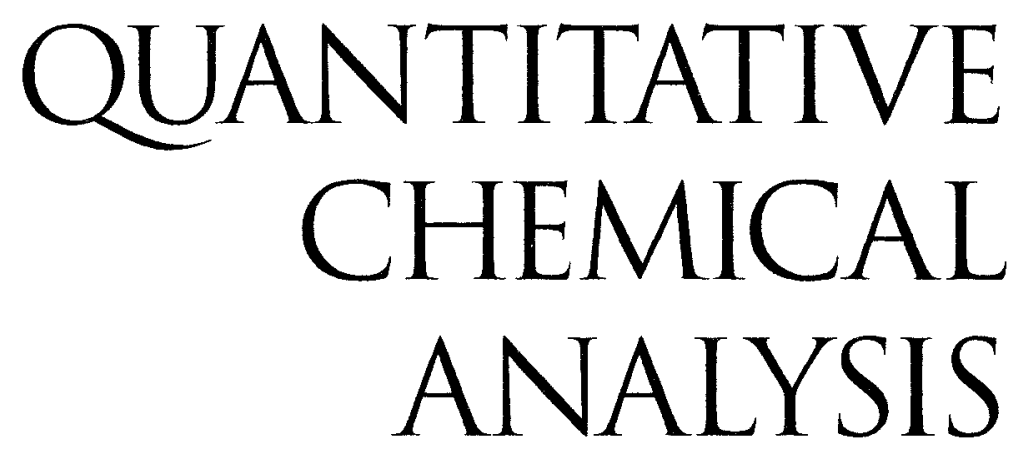

$\mathrm{Na} \mathrm{Li}$

Peking University, China

John J. Hefferren

Peking University, China \& University of Kansas, USA

Ke'an $\mathrm{Li}$

Peking University, China 
Published by

World Scientific Publishing Co. Pte. Ltd.

5 Toh Tuck Link, Singapore 596224

USA office: 27 Warren Street, Suite 401-402, Hackensack, NJ 07601

UK office: 57 Shelton Street, Covent Garden, London WC2H $9 \mathrm{HE}$

\section{Library of Congress Cataloging-in-Publication Data}

$\mathrm{Li}, \mathrm{Na}, 1965-$

Quantitative chemical analysis / by Na Li (Peking University, China), John J Hefferren (Peking University, China \& University of Kansas, USA) \& Ke'an Li (Peking University, China).

pages $\mathrm{cm}$

Includes bibliographical references and index.

Summary: "Covers both fundamental and practical aspects of chemical analysis. A textbook for Freshmen or sophomores"-- Provided by publisher.

ISBN 978-9814452281 (alk. paper)

1. Chemistry, Analytic--Quantitative. I. Hefferren, John J. II. Li, Ke'an. III. Title.

QD I01.L63 2013

$543.1-\mathrm{dc} 23$

2013004455

\section{British Library Cataloguing-in-Publicatiou Data}

A catalogue record for this book is available from the British Library.

Copyright (C) 2013 by $\mathrm{Na} \mathrm{Li}$, John J. Hefferren, Ke'an Li

The Work was originally published by Peking University Press in 2009.

This edition is published by World Scientific Publishing Co Pte Ltd by arrangement with Peking University Press, Beijing, China.

All rights reserved. No reproduction and distribution without permission. 


\section{PREFACE}

$\mathrm{T}$

his text brings together the individuals and the desire to develop a text for undergraduate students who have English as a second language. Our initial focus was undergraduate students with chemistry major in the College of Chemistry and Molecular Engineering, Pcking University, Beijing, China, but now we hope and expect that other undergraduate students may be able to learn more easily with this text as they cope with the English language and the essentials of analytical chemistry.

\section{Lecture Series Leading to Text:}

The one semester course in analytical chemistry in English for undergraduate students was initiated by Professor Li Ke'an in February 2005 with Dr. Li Na as the presenter of one 2 hour lecturc each week for 15 weeks. The size of the lecture room limited the number of students to 50 .

Each year the students prepare presentations of their science project reports. The audience of their peers grades the oral presentations of those students who volunteered and were selected to give oral presentations. Competition for being included among the oral presenters has been impressive. Student discussion, grading of the presenters and the presentations bring forth a profound bonding. Each of us in the lecture room feels the shocs worn by another.

As we introduced different examples and illustrations to the lecture series, these quickly became ideas for the coming analytical chemistry text. In Chapter 1, the Human Genome Project was used to show the power and success possible when analytical chemists join forces to bring the minds and resources of the academic community to focus on a goal. The project is indeed a road map of problem solving using new and different technologies plus automation to resolve analytical road blocks to meet the time constraints of the Genome Project thus opening research opportunities for decades. A global environmental need brought together another group of scientists in the concluding Chapter 10 to address the ever present need to monitor drinking water contamination throughout the world. We selected arsenic as one example of the world-wide need for simple, sensitive, cost effective analytical methods to monitor drinking water. Again, we tried to show the rationale dictating 
the path taken by scientists to deal with the specifics of water treatment analysis. Fundamental to analytical chemistry are the problem solving tools that scientific minds select for each set of circumstances. This analytical chemistry text lists many of the scientific minds of analytical chemistry from Berthelot and Jungfleisch in 1872 to those of 2009 who have provided the best tool for the situation.

\section{Peking University Lecture Team:}

This text has been assembled and is based upon more than a quarter of century of teaching analytical chemistry at Peking University. Many examples and illustrative problems in this text have been taken from previous textbooks in Chinese written by the Peking University Team Teaching Program. This text was written by Dr. Li Na and edited by Professor John Hefferren with the guidance of Professor Li Ke' an. Some of the Chinese teaching style has been used in the text to maintain ties to the Chinese traditions; however, references and terminology of established analytical chemistry books published in the world have also been used. It is hoped that this blend of perspective is helpful and interesting to all readers.

\section{Authors :}

Li Na is associate prolessor, Analytical Chemistry Division, College of Chemistry and Molecular Engineering, Peking University, Beijing, China. John J. Hefferren is guest professor of Peking University and adjunct professor, Department of Pharmaceutical Chemistry, School of Pharmacy, University of Kansas, Lawrence, Kansas, USA. Li Ke' an is professor and vice provost, Peking University, Beijing, China.

\section{Acknowledgements :}

Graduate students Zou Mingjian, Xu Xiao, Wang Xinyin, Chen Qiang and Chen Yang helped in many ways to the completion of the text. The text was supported in part by Peking University and prepared by the editorial staff.

We gratefully acknowledge the influence of those that we consider our chemistry colleagues who have written the texts of the world. It is our profound hope that each of you will join us in continuing to nurture the rich tradition of analytical chemistry.

Li Na, Ph. D.

John J. Hefferren, Ph. D.

Li Ke’an, professor 


\section{CONTENTS}

\section{CHAPTER 1 INTRODUCTION OF ANALYTICAL CHEMISTRY 1}

1.1 What is Analytical Chemistry 2

1.2 Steps in the Development of an Analytical Method 5

1.3 Classification of Quantitative Analytical Methods 7

1.3.1 Chemical Analysis 7

1.3.2 Instrumental Analysis 8

1. 4 Principles of Volumetric Titration 8

1.4. 1 Basic Terms 9

1.4.2 Requirements of Titration Reactions 9

1.4. 3 Classification of Titration Processes 10

1.4. 4 Primary Standards and Standard Solutions 10

1.4.5 Basic Apparatus in Chemical Analyses 11

1. 5 Calculations in Volumetric Titration 15

1.5.1 Preparation of Standard Solutions 15

1.5.2 Titration Results 18

\section{CHAPTER 2 DATA ANALYSIS 22}

2. 1 Error and Classification 23

2.1.1 Accuracy and Precision 23

2.1.2 Errors and Deviation 24

2.1.3 Systematic and Random Errors 25

2. 2 Distribution of Random Errors 26

2.2.1 Frequency Distribution 27

2.2.2 Normal Distribution 28

2.2.3 Predicting the Probability of Random Errors-Area under Gaussian Curve 30

2. 3 Statistical Data Treatment 31

2.3. 1 Estimation of Population Mean $(\mu)$ and Population Standard Deviation $(\sigma) \quad 31$

2.3.2 Confidence Interval for Population Mean 34

2.3.3 Statistical Aids to Hypothesis Testing 37

2.3.4 Detection of Gross Errors 42 
2. 4 Propagation of Error 43
2.4. 1 Systematic Errors
43
2.4.2 Random Errors (Standard Deviation)
2.4.3 Maximum Errors $\left(E_{R}\right) \quad 44$
2. 4. 4 Distribution of Errors 44

2.5 Significant Figure Convention 45

2.5.1 Significant Figures 45

2.5.2 Numerical Rounding in Calculations 47

\section{CHAPTER 3 ACID-BASE EQUILIBRIUM $\mathbf{5 0}$}

3. 1 Equilibrium Constants and Effect of Electrolytes

3. 2 Acid-base Reactions and Equilibria 53

3.2.1 Acid and Base-Bronsted Concept 53

3.2.2 Dissociation of Acid or Base and Acid-base Equilibria 55

3.2.3 Magnitude of Dissociating Species at a Given pH: $x$-values 57

3. 3 Solving Equilibrium Calculations Using pH Calculations as an Example

3.3.1 General Approaches (Systematic Approaches) 61

3.3. 2 pH Calculations 64

3. 4 Buffer Solutions 71

3.4.1 pH Calculations of Buffer Solutions 71

3.4.2 Buffer Capacity 72

3.4.3 Preparation of Buffers 74

\section{CHAPTER 4 ACID-BASE TITRATION 78}

4. 1 Acid/Base Indicators 79

4.1.1 Principle 79

4.1.2 Examples 80

4. 1.3 Titration Errors 82

4.1.4 Factors Influencing Performance 82

4. 2 Titration Curves and Selection of Indicators 83

4.2.1 Strong Acids (Bases) 83

4.2.2 Monoprotic Acids (Bases) 86

4.2. 3 Strong and Weak Acids (Bases) 91

4.2. 4 Polyfunctional Weak Acids (Bases) 92

4.2.5 Mixture of Weak Acids (Bases) 95

4. 3 Titration Error Calculations 95

4. 3. 1 Strong Acids (Bases) 95 

4.3.2 Monoprotic Weak Acids (Bases)
96
4. 3.3 Polyfunctional Acids (Bases)
97

4. 4 Preparation of Standard Solutions

98
4.4.1 Standard Acid Solutions 98
4. 4.2 Standard Base Solutions 99
4. 4.3 The Carbonate Error 100

4. 5 Examples of Acid-base Titrations 101

4.5.1 Determination of Total Alkalinity 101

4.5.2 Determination of Nitrogen 102

4.5.3 Determination of Boric Acid 103

4.6 Acid-base Titrations in Non-aqueous Solvents 104

4.6.1 Non-aqueous Solvents 104

4.6.2 Examples of Non-aqueous Titrations 105

\section{CHAPTER 5 COMPLEXATION REACTION AND COMPLEXOMETRIC TITRATION $\quad 108$}

5.1 Complexes and Formation Constants 109

5.1.1 Formation Constants 109

5.1.2 Concentration of $\mathrm{ML}_{, n}$ in Complexation Equilibria 111

5.1.3 Ethylenediaminetetraacetic Acid (EDTA) and Metal-EDTA Complexes 113

5.1.4 Side Reaction Coefficients and Conditional Formation Constants in Complexation Reactions 115

5.2 Metallochromic Indicators 122

5.2.1 How a Metallochromic Indicator Works 122

5.2.2 Color Transition Point pM ((pM) $)$ for Metallochromic Indicators 123

5.2.3 Frequently Used Metallochromic Indicators 125

5.3 Titration Curves and Titration Errors 126

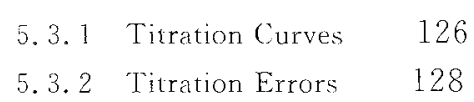

5.3.3 $\mathrm{pH}$ Control in Complexometric Titrations 129

5. 4 Selective Titrations of Metal Ions in the Presence of Multiple Metal Ions 130

5.4.1 Selective Titration by Regulating pH 131

5.4.2 Selective Titration Using Masking Reagents 133

5. 5 Applications of Complexometric Titrations 137

5.5.1 Buffer Selection in Complexometric Titrations

5.5.2 Titration Methods and Applications 138

5.5.3 Preparation of Standard Solutions 142 
6.1 Standard Electrode Potentials, Formal Potentials and Redox Equilibria 147

6.1.1 Standard Electrode Potentials 147

6.1.2 The Nernst Equation and Formal Potentials 149

6.1.3 Factors Affecting the Formal Potential 150

6. 1.4 The Equilibrium Constant of Redox Reaction 154

6.2 Factors Affecting the Reaction Rate 155

6.2.1 Concentrations 156

6.2.2 Temperature 157

6.2.3 Catalysts and Reaction Rate 157

6.2.4 Induced Reaction 157

6.3 Redox Titrations 158

6.3.1 Constructing Redox Titration Curves 158

6.3.2 Indicators 162

6.3.3 Auxiliary ()xidizing and Reducing Agents 164

6.4 Examples of Redox Titrations 165

6.4.1 Potassium Permanganate $\left(\mathrm{KMn}()_{1}\right) \quad 165$

6.4.2 Potassium Dichromate $\left(\mathrm{K}_{2} \mathrm{Cr}_{2} \mathrm{O}_{7}\right) \quad 168$

6.4.3 Iodine: Iodimetry and lodometry 169

6.4. 4 Potassium Bromate $\left.(\mathrm{KBr})_{3}\right) \quad 173$

6.4.5 Ceric Sulfate $\left(\mathrm{Ce}\left(\mathrm{SO}_{1}\right)_{2}\right) \quad 174$

7.1 Precipitation Equilibria and Solubility 178

7.1.1 Solubility of Precipitates in Pure Water 178

7.1.2 Ionic Strength and the Solubility of Precipitates 178

7.1.3 Common Ion and the Solubility of Precipitates 179

7.1.4 $\mathrm{pH}$ and the Solubility of Precipitates 179

7.1.5 Complexing Agents and the Solubility of Precipitates 182

7.2 Precipitation Titrations 184

7.2.1 Titration Curves 184

7.2.2 Examples of Methods Classified by Endpoint Indication 186

7.2.3 Preparation of Standard Solutions 189

\section{3 Precipitation Gravimetry 190}

7.3.1 Classification of Gravimetric Methods of Analysis 190

7.3.2 General Procedure and Requirements for Precipitation 190 
7.3.3 Precipitate Formation 192

7.3.4 Obraining High Purity Precipitates 193

7.3.5 Experimental Considerations 197

7.3.6 Examples of Organic Precipitating Reagents 200

\section{CHAPTER 8 SPECTROPHOTOMETRY 206}

8.1 Principle of Spectrochemical Analysis 207

8.1.1 Properties of Elec1romagnetic Radiation 207

8.1.2 Interaction of Electromagnetic Radiation with Matter 208

8.1.3 Beer's Law, the Quantitative Principle of Light Absorption 213

8.1.4 Limitations to Beer's Law 216

8.2 Principles of Instrumentation 217

8.2.1 Instrumentation 217

8.2.2 Instrumental Errors in Absorption Measurement 226

8. 3 Applications of Spectrophotometry 226

8.3.1 Single Component Analyses 226

8.3.2 Multicomponent Analyses 228

8.3.3 Spectrophotometric Titrations 230

8.3.4 Studies of Complex Formation in Solutions 231

8.3.5 Measurements of Dissociation Constants of

Organic Acids/Bases 233

CHAPTER 9 INTRODUCTION TO ANALYTICAL SEPARATION 238

9.1 General Considerations of Separation Efficiency 239

9.2 Separation by Precipitation 241

9.2.1 Inorganic Precipitants 241

9.2.2 Organic Precipitants 242

9.2.3 Coprecipitation of Species in Trace Amounts for Separation 243

9.2.4 Improving the Selectivity of Precipitation Separation 244

9.3 Separation by Extraction 245

9.3.1 Principles for Liquid-liquid Extraction 245

9.3.2 Percent Extraction 247

9.3.3 Extraction of Inorganic Species 249

9.3.4 Other Extraction Methods 254

9.4 Separation by Ion Exchange 257

9.4.1 Ion Exchange Resins 257

9.4.2 Cross-linkage and Exchange Capacity 259 
9.4.3 Ion Exchange Equilibria 260

9.4.1 Applications of lon Exchange Separation 261

9.5 Separation by Chromatography 263
9.5.1 Classification 263
9.5.2 Chromatogram 264
9.5.3 Column Chromatography 265
9.5.4 Planar Chromatography 266

CHAPTER 10 SOLVING A REAL ANALYTICAL PROBLEM 271
10. 1 Definition of the Analytical Problem
272
10.2 Literature Review 273
10.3 Choosing a Method 275
10.4 Developing and Evaluating the Method 276
10.4.1 Solectivity 276
10.4.2 Accuracy 277
10.4.3 Sensitivity and Linear Dynamic Range 279
10.5 Conclusion 280

\section{APPENDICES 281}

Appendix A References 281

Appendix B Indicators 283

Appendix C Activity Coefficients $(\gamma)$ for Ions at $25^{\circ} \mathrm{C} \quad 285$

Appendix D Constants for Acid-base, Complexometric, Redox, and Precipitation Titrimetry 286

Appendix E Molecular Masses 299

ANSWERS $\quad 302$

INDEX 305

PERIODIC TABLE OF THE ELEMENTS 309 